\title{
Health-related quality of life (Nottingham Health Profile) in patients with endometriomas: correlation with clinical variables and self-reported limitations
}

Karolina Chmaj-Wierzchowska, Paweł Rzymski, Małgorzata Wojciechowska, Ilona Parda, Maciej Wilczak

Department of Mother's and Child's Health, Poznan University of Medical Science, Poznan, Poland

Submitted: 10 October 2018

Accepted: 1 January 2019

Arch Med Sci 2020; 16 (3): 584-591

DOI: https://doi.org/10.5114/aoms.2019.82744

Copyright (c) 2019 Termedia \& Banach

\section{Abstract}

Introduction: Endometriosis is a chronic disease that involves the development of endometrium outside the uterine cavity with pain component predominance. The aim of the study was to discuss the occurrence of health problems in patients with endometriomas and simple cysts and the effect of these problems on the daily functioning of the patients.

Material and methods: The study included patients $(n=40)$ treated laparoscopically and/or by laparotomy due to lesions in the form of endometriomas or simple cysts. The control group $(n=36)$ consisted of healthy patients of the Gynecological Clinic, with no changes in adnexa confirmed in vaginal ultrasound examination. The original authors' questionnaire and the Nottingham Health Profile Questionnaire (NHP) were used as research tools.

Results: Analysis of the correlation with Spearman's test demonstrated a statistically significant relationship between the size of the tumor and the occurrence of sleep disorders only in the group of women suffering from endometriomas $(r=-0.348 ; p=0.041)$. Women with endometriomas significantly more often reported problems (Cramer's $V$ ) in the sphere of "paid work" ( $p<0.001)$, "housework" $(p<0.001)$, in social life $(p<0.001)$, problems in sexual life $(p<0.001)$ as well as problems in continuing hobbies $(p<0.001)$ and in spending free time $(p<0.001)$.

Conclusions: Since the stage of endometriosis does not correlate with subjective complaints, it seems that an additional routine evaluation of quality of life, including an assessment of the severity of the disease, is warranted. Routine use of the Nottingham Health Profile Questionnaire in patients with endometriosis can improve also the assessment of the treatment.

Key words: endometriomas, endometriosis, simple cysts, health problems, Nottingham Health Profile Questionnaire.

\section{Introduction}

Endometriosis is a chronic disease that involves the development of endometrium outside the uterine cavity with pain component predominance [1]. It occurs in the form of implants and peritoneal adhesions as well as endometriomas. Single or multiple cysts, often large in size, are colloquially referred to as "chocolate" due to their thick, brown liquid content [2]. The main symptom of endometriosis is chronic pain,

\section{Corresponding author:} Assoc. Prof. Paweł Rzymski $\mathrm{MD}, \mathrm{PhD}$

Department of Mother's and Child's Health Poznan University of Medical Science 33 Polna St 60535 Poznan, Poland Phone: +48 605393096 E-mail: parzymsk@ gpsk.am.poznan.pl 
occurring with typical cyclicality and severity of pain during menstruation [3]. The degree of pain experienced in endometriosis is not proportional to the severity of the disease. The presence of small foci of peritoneal endometriosis can cause severe pain, while large cysts may not cause any complaints [4]. In addition, pain in the course of endometriosis is subjective and due to non-specific clinical symptoms is recognized by accident, for example, during medical procedures [3]. However, pain associated with the disease negatively affects the quality of life, limiting professional activity and social contacts $[5,6]$. The patients who experience pain more often show worse quality of life and mental health and may suffer from depression compared to women who do not suffer from pain due to endometriosis [7]. Women suffering from endometriosis assess their quality of life, including sexual functioning, as lower than women without endometriosis, and even women with other gynecological diseases [8].

The concept of quality of life is difficult to define, but it is an indispensable element for the functioning of each individual. The study of quality of life now follows a holistic approach for every patient. The study of patient's life quality is a broad-spectrum issue that combines the clinical aspects of a given disease entity as well as the psychological aspect in the medical care of the patient. These two examinations cannot be separated. Both aspects must be included in the patient's description. We often deal with the patient only from the medical side, determining the effect of therapy on the further development of the disease, and do not evaluate the effect of the patient's feelings on the existing situation. Quality of life is an extremely subjective value and depends to a large extent on mental state, personality traits, preferences, value system, etc. For example, the same symptom - limitation of physical activity - can cause a significant reduction in the quality of life in a subjective assessment in one person, while it may only be a small inconvenience in another person with greater restrictions of this activity [9].

There are various scientific tools applied to assess the quality of life among patients, each one emphasizes certain aspects. The Nottingham Health Profile is used to measure health problems perceived by the patient and to assess the effect of these problems on daily functioning. It is one of the most widely used tools, validated in different languages. It has also been proved to correlate strongly with other tools, thus showing good repeatability and reliability. It was compared with the SF-36, Merle d'Aubigne Score (MDA), with good agreement [10-12]. It is also worth noting that the NHP was more sensitive to the physical aspect of the disease, whereas the SF-36 was more coherent in evaluating social functioning [11]. By contrast with the widely used quality of life (QoL) questionnaires, some tools for more specific application are also being developed, such as the Endometriosis Health Profile (EHP-5) or the World Endometriosis Research Foundation (WERF) Global Study on Women's Health (GSWH) instrument $[13,14]$.

The aim of the study was to discuss the occurrence of health-related problems in patients with endometriomas and simple cysts and the effect of these problems on the daily functioning of the patients.

\section{Material and methods}

The study consisted of patients $(n=40)$ treated laparoscopically and/or by laparotomy, at the Gynecological and Obstetrics Clinical Hospital of the Medical University of Poznan in 2017 due to lesions in the form of endometriomas or simple cysts. The control group $(n=36)$ consisted of healthy patients of the Gynecological Clinic, with no changes in the adnexa, confirmed in vaginal ultrasound examination.

The criteria for patient qualification to the analyzed groups were as follows: negative obstetric history, good health status without coexisting diseases, intraoperative diagnosis of endometriomas or simple cyst, and no pathological changes in the adnexa in the control group. The diagnosis of endometriomas was based on a cystic ovarian mass filled with hyperechogenic fluid (Aloka SSD3500, Japan) and confirmed after surgery by routine pathologic examination.

A total of 76 women, aged $18-56$, were included in the study. A diagnostic survey was selected as a method to fulfill the research goal and to obtain answers to the research questions. The research technique applied was in the form of questionnaires. The original authors' questionnaire and the Nottingham Health Profile Questionnaire (NHP) were used as research tools. The Nottingham Health Profile Questionnaire was used to measure health problems perceived by the patient and to assess the effect of these problems on daily functioning. We used the Polish validated adaptation of the NHP as previously described in the literature [10]. The patient's questionnaires were filled out on their own, one day before the operative procedure and after a routine annual medical visit in the control group.

On the basis of the obtained answers qualification to the group of women with endometriomas or benign lesions of simple cyst character was a histopathological examination obtained as a result of laparoscopy and/or laparotomy. The qualification criterion for surgical treatment was the 
size of the cyst $>4 \mathrm{~cm}$ or pain in case of smaller lesions. All the patients with endometriomas has previously unsuccessful treatment with oral contraceptives, not resulting in pain or dyspareunia reduction, conception or cyst disappearance. After intraoperative histopathological verification the patients were divided into two groups; endometriomas and simple cysts.

The original questionnaire consisted of ten closed questions. Most of the questions related to age, education, place of residence, marital status and financial situation, number of children and number of miscarriages and health status.

The Nottingham Health Profile is a general patient self-evaluation of subjective health status in a number of areas and can be completed in $5 \mathrm{~min}$ [15]. This questionnaire consists of two parts. The first, fundamental one, concerns currently experienced problems related to physical, psychological and social functioning associated with health status. The first part focuses on 6 dimensions of subjective state of health and comprises 38 dichotomized (yes/no) items, 8 of which deal with pain, 3 with vital energy, 5 with sleep disorders, 8 with physical fitness (mobility), 9 with emotional reaction and 5 with social isolation [16]. The second part comprises life areas affected $[17,18]$ and consists of 7 items referring to paid work, housework, social life, family life, sexual life, interests and hobbies, and the use of free time [17]. Both parts are dichotomized and the scoring from part one is weighted. The scoring has an upper value of 100 corresponding to the greater severity of health problems. The weights in part one range from 5.83 to 39.2 depending on the question and are summarized in a scoring sheet. The second part has only yes/no answers and in the case of uncertainty the patient is asked to select which is more true at this time [18]. The questionnaire was developed in 1975 in Nottingham and has been used by a number of organizations worldwide. The NHP has 24 validated language versions and has also been used in clinical research studies, especially when treatment effectiveness is considered.

The respondents gave answers to the questions in the questionnaires independently, anonymously on the day before surgery (groups with lesions in adnexa) in the hospital and after a medical visit to the gynecological clinic. The respondents were informed about the purpose of the study. Blood for the Ca125, HE4, CEA, AFP assays was collected on the day of admission to the hospital, i.e., the day before surgery, fasting in the morning.

\section{Ethics statement}

Patient enrollment methods, ways of obtaining the research material, and its storage were ap- proved by the Bioethics Committee at the Poznan University of Medical Sciences (Resolution No. 1127/18).

\section{Statistical analysis}

The statistical analysis of quantitative data was presented as mean values and standard deviation (SD), and additionally the medians (Me) were calculated. Significance of differences in mean values for parameters different from a normal distribution or with heterogeneous variances for two groups of variables was verified by the non-parametric Mann-Whitney $U$ test. The statistical analysis for qualitative data from the questionnaire regarding the characteristics of the persons examined was presented in the form of a numerical value of people in a given category (n). In order to compare the qualitative characteristics between the groups, the $\chi^{2}$ independence test was used and the effect strength was estimated based on Cramer's V contingency coefficient. Spearman's rank correlation coefficients were calculated to assess the occurrence of dependencies between particular variables and the strength of this relationship (if at least one of the parameters had a non-normal distribution).

Statistical analysis of the results obtained in individual groups was performed using the Kruskal-Wallis test for independent samples, and Dunn's post-hoc tests, while the correlation was performed using Spearman's correlation coefficients. The limit of significance was assumed as $p=0.05$ in all statistical tests.

\section{Results}

The endometriomas $(E)$ group included women ( $n=23$ ) with histopathologically confirmed endometriomas, aged $29.83 \pm 5.68$ years, median (Me) 29 years. The group of simple cysts $(P)$ included female patients $(n=17)$ after surgical treatment of benign ovarian lesions, aged $43 \pm 11.30$ years, $\mathrm{Me}=43$ years. The control group $(\mathrm{K})$ comprised healthy women undergoing routine, annual gynecological examination, aged $28.31 \pm 4.05$ years, $\mathrm{Me}=29$ years .

\section{General characteristics of the examined groups}

All women reported having a good general condition without coexisting diseases. One woman in group $\mathrm{K}$ had 2 children; no miscarriages were reported in the interview. Three patients in group $\mathrm{P}$ had 2 children, the remainder, 1 child; miscarriages had occurred in 7 women. In group E, 1 patient had 2 and 1 child; miscarriages had occurred in 2 women. The general characteristics of the examined groups are presented in Table I. The mean 
values of the size of ovarian tumors, the level of CEA, AFP, Ca125, HE4 markers in particular groups are presented in Table II. Dyspareunia was reported in 17/23 (73.9\%) patients from group E, 5/17 (29.4\%) from group $P$ and in $3 / 36$ (8.3\%) from group $\mathrm{K}$.

\section{Six dimensions of subjective health status}

Comparing the subjective dimensions of health status in particular groups it was found that the group of patients with endometriosis had a significantly higher intensity of "pain", "emotional reactions", "sleep disorders" and "physical fitness" variables compared to other groups. There were no significant differences for "social isolation" and "vital energy" variables (Table III). Analysis of the correlation with Spearman's test demonstrated a statistically significant relationship between the size of the tumor and the occurrence of sleep disorders only in the group of women suffering from endometriosis $(r=-0.348 ; p=0.041)$.

\section{Six spheres of life}

Women with endometriomas significantly more often reported problems in the sphere of "paid work" (Cramer's V 0.721, $p<0.001$ ) and in "housework" (Cramer's V 0.648, $p<0.001$ ), in social life (Cramer's $\vee 0.747, p<0.001$ ), problems in

Table I. Characteristics of examined groups

\begin{tabular}{|c|c|c|c|}
\hline Parameter & $\begin{array}{l}\text { Control } \\
(n=36)\end{array}$ & $\begin{array}{l}\text { Simple } \\
(n=17)\end{array}$ & $\begin{array}{l}\text { Endometriomas } \\
\qquad(n=23)\end{array}$ \\
\hline Age [years] & 28.31 & 41.18 & 29.83 \\
\hline \multicolumn{4}{|l|}{ Education: } \\
\hline Primary & 1 & 0 & 0 \\
\hline Vocational & 0 & 0 & 1 \\
\hline Secondary & 2 & 5 & 3 \\
\hline Higher & 33 & 12 & 19 \\
\hline \multicolumn{4}{|l|}{ Place of residence: } \\
\hline Village & 3 & 0 & 1 \\
\hline City up to 50 thousand & 2 & 0 & 3 \\
\hline City from 50 to 200 thousand & 6 & 0 & 1 \\
\hline City from 200 to 500 thousand & 5 & 6 & 1 \\
\hline City above 500 thousand & 20 & 11 & 17 \\
\hline \multicolumn{4}{|l|}{ Marital status: } \\
\hline Spinster & 14 & 0 & 10 \\
\hline Married & 22 & 17 & 13 \\
\hline Single & 0 & 0 & 0 \\
\hline \multicolumn{4}{|l|}{ Occupational status: } \\
\hline Physical work & 2 & 1 & 2 \\
\hline Mental work & 28 & 0 & 15 \\
\hline Pension & 3 & 0 & 1 \\
\hline Retirement & 0 & 0 & 0 \\
\hline Studies & 3 & 0 & 1 \\
\hline Does not work & 0 & 16 & 4 \\
\hline \multicolumn{4}{|l|}{ Average monthly income per person: } \\
\hline Less than 500 PLN & 0 & 0 & 1 \\
\hline 500-1000 PLN & 6 & 3 & 3 \\
\hline Above 1000 PLN & 30 & 13 & 19 \\
\hline
\end{tabular}


Table II. Size of ovarian tumors and levels of CEA, AFP, Ca125, HE4

\begin{tabular}{|c|c|c|c|c|}
\hline Group & Minimum & Maximum & Mean & Standard deviation \\
\hline \multicolumn{5}{|l|}{ Simple: } \\
\hline Size of right ovary tumor [mm] & 3 & 85 & 35.10 & 30.00 \\
\hline Size of left ovary tumor [mm] & 2 & 70 & 33.59 & 19.12 \\
\hline CEA & 0.62 & 2.76 & 1.26 & 0.58 \\
\hline AFP & 0.98 & 1.87 & 1.31 & 4.48 \\
\hline HE4 & 33.39 & 78.34 & 54.81 & 13.39 \\
\hline CA125 & 4.05 & 18.23 & 12.09 & 4.02 \\
\hline \multicolumn{5}{|l|}{ Endometriomas: } \\
\hline Size of right ovary tumor [mm] & 26 & 94 & 45.00 & 25.95 \\
\hline Size of left ovary tumor [mm] & 22 & 66 & 42.44 & 12.41 \\
\hline CEA & 0.43 & 1.98 & 1.14 & 0.43 \\
\hline AFP & 1.21 & 3.79 & 2.26 & 0.78 \\
\hline HE4 & 36.42 & 72.03 & 56.54 & 8.94 \\
\hline CA125 & 19.08 & 81.25 & 41.07 & 17.16 \\
\hline
\end{tabular}

sexual life (Cramer's V 0.682, $p<0.001$ ) as well as problems in practicing hobbies (Cramer's $\vee 0.714$, $p<0.001)$ and in spending free time (Cramer's $\mathrm{V}$ $1.000 ; p<0.001)$. The occurrence of problems was not affected by place of residence, average income per person, marital status or occupational status. Summing up the problems reported as "inconvenience in daily life" it was found that the group of patients suffering from endometriosis had significantly higher values of this variable than the other two groups (Table III).

\section{Discussion}

According to the definition of the World Health Organization (WHO), quality of life is "the individual's perception of their position in life in the context of the culture and value systems in which they live and in relation to the goals, expectations and standards determined by environmental conditions" [19]. Chronic pain, occurring with typical cyclicality and severity, may significantly reduce the quality of life of women with endometriosis. The quality of life indices include the ability to play previous life roles, adaptability, psychological well-being and functioning within social groups [20]. A meta-analysis of 42 articles conducted by Culley et al. regarding the current state of knowledge on the social and psychological effects of endometriosis on women's lives clearly showed that endometriosis has a significant social and psychological impact on everyday activities, intimate relationships, planning and having children, education and work, mental health and emotional well-being [21]. In the psychological dimension, apart from physical pain, mental suffering is also observed. In addition to losing health, the disease leads to loss of safety, self-confidence, and often hope. The pain comes unexpectedly, hindering everyday functioning. Physical symptoms of pain and difficulty in regulating emotions through psychological stress can negatively affect the quality of life associated with health (HRQoL) in women with endometriosis. Márki et al. [22] conducted a study among 193 women, in whom they evaluated the extent to which pain symptoms, anxiety, depression, stress, and emotional regulation affected the health of women with endometriosis. $54.79 \%$ of participants showed anxiety, and depressive symptoms were observed among $20.3 \%$. Strong physical pain was directly, and difficulties in the regulation of emotions indirectly, related to the deterioration of general HRQoL. The researchers also observed that physical pain had a larger direct standardized effect on physical HRQoL and had no significant direct effect on mental HRQoL. Moreover, both physical pain and difficulty in regulating emotions had a significant indirect effect on mental HRQoL [22]. This is to our knowledge the first study using the NHP in patients with endometriosis treated surgically. There are some papers concerning surgical treatment in other specialties with assessment of QoL by the NHP [12]. They also showed a perfect correlation with many clinical aspects of the disease, as in the case of osteoarthritis. Knee flexion, angle range, duration of the disease, pain, physical life and sociologic restric tions were strongly correlated with the NHP [23] 
Table III. Comparison of subjective dimensions of health status in individual groups

\begin{tabular}{|c|c|c|c|c|c|c|}
\hline \multirow[t]{2}{*}{ Factor 1} & \multirow[t]{2}{*}{ (I) Group } & \multirow[t]{2}{*}{ (J) Group } & \multirow[t]{2}{*}{$\begin{array}{l}\text { Standard } \\
\text { error }\end{array}$} & \multirow[t]{2}{*}{ Significance $^{b}$} & \multicolumn{2}{|c|}{$\begin{array}{l}95 \% \text { confidence interval } \\
\text { for significance }{ }^{b}\end{array}$} \\
\hline & & & & & Lower limit & Upper limit \\
\hline \multirow[t]{6}{*}{ Energy } & \multirow[t]{2}{*}{ Control } & Simple & 0.169 & 0.277 & -0.152 & 0.521 \\
\hline & & Endometriomas & 0.153 & 0.931 & -0.292 & 0.318 \\
\hline & \multirow[t]{2}{*}{ Simple } & Control & 0.169 & 0.277 & -0.521 & 0.152 \\
\hline & & Endometriomas & 0.183 & 0.353 & -0.537 & 0.194 \\
\hline & \multirow[t]{2}{*}{ Endometriomas } & Control & 0.153 & 0.931 & -0.318 & 0.292 \\
\hline & & Simple & 0.183 & 0.353 & -0.194 & 0.537 \\
\hline \multirow[t]{6}{*}{ Pain } & \multirow[t]{2}{*}{ Control } & Simple & 0.462 & 0.857 & -0.838 & 1.004 \\
\hline & & Endometriomas & 0.419 & 0.000 & -3.100 & -1.429 \\
\hline & \multirow[t]{2}{*}{ Simple } & Control & 0.462 & 0.857 & -1.004 & 0.838 \\
\hline & & Endometriomas & 0.502 & 0.000 & -3.349 & -1.347 \\
\hline & \multirow[t]{2}{*}{ Endometriomas } & Control & 0.419 & 0.000 & 1.429 & 3.100 \\
\hline & & Simple & 0.502 & 0.000 & 1.347 & 3.349 \\
\hline \multirow[t]{6}{*}{ Emotions } & \multirow[t]{2}{*}{ Control } & Simple & 0.295 & 0.296 & -0.277 & 0.898 \\
\hline & & Endometriomas & 0.268 & 0.303 & -0.811 & 0.255 \\
\hline & \multirow[t]{2}{*}{ Simple } & Control & 0.295 & 0.296 & -0.898 & 0.277 \\
\hline & & Endometriomas & 0.321 & 0.071 & -1.227 & 0.051 \\
\hline & \multirow[t]{2}{*}{ Endometriomas } & Control & 0.268 & 0.303 & -0.255 & 0.811 \\
\hline & & Simple & 0.321 & 0.071 & -0.051 & 1.227 \\
\hline \multirow[t]{6}{*}{ Sleep } & \multirow[t]{2}{*}{ Control } & Simple & 0.360 & 0.016 & 0.171 & 1.607 \\
\hline & & Endometriomas & 0.327 & 0.941 & -0.675 & 0.627 \\
\hline & \multirow[t]{2}{*}{ Simple } & Control & 0.360 & 0.016 & -1.607 & -0.171 \\
\hline & & Endometriomas & 0.392 & 0.022 & -1.693 & -0.133 \\
\hline & \multirow[t]{2}{*}{ Endometriomas } & Control & 0.327 & 0.941 & -0.627 & 0.675 \\
\hline & & Simple & 0.392 & 0.022 & 0.133 & 1.693 \\
\hline \multirow{6}{*}{$\begin{array}{l}\text { Social } \\
\text { isolation }\end{array}$} & \multirow[t]{2}{*}{ Control } & Simple & 0.065 & 0.091 & -0.018 & 0.241 \\
\hline & & Endometriomas & 0.059 & 0.063 & -0.006 & 0.229 \\
\hline & Simple & Control & 0.065 & 0.091 & -0.241 & 0.018 \\
\hline & & Endometriomas & 0.071 & 1.000 & -0.141 & 0.141 \\
\hline & Endometriomas & Control & 0.059 & 0.063 & -0.229 & 0.006 \\
\hline & & Simple & 0.071 & 1.000 & -0.141 & 0.141 \\
\hline Physical & Control & Simple & 0.251 & 1.000 & -0.500 & 0.500 \\
\hline fitness & & Endometriomas & 0.227 & 0.000 & -1.410 & -0.503 \\
\hline & Simple & Control & 0.251 & 1.000 & -0.500 & 0.500 \\
\hline & & Endometriomas & 0.272 & 0.001 & -1.499 & -0.414 \\
\hline & Endometriomas & Control & 0.227 & 0.000 & 0.503 & 1.410 \\
\hline & & Simple & 0.272 & 0.001 & 0.414 & 1.499 \\
\hline Inconvenience & Control & Simple & 0.236 & 0.162 & -0.137 & 0.804 \\
\hline & & Endometriomas & 0.214 & 0.000 & -5.050 & -4.197 \\
\hline & Simple & Control & 0.236 & 0.162 & -0.804 & 0.137 \\
\hline & & Endometriomas & 0.257 & 0.000 & -5.468 & -4.445 \\
\hline & Endometriomas & Control & 0.214 & 0.000 & 4.197 & 5.050 \\
\hline & & Simple & 0.257 & 0.000 & 4.445 & 5.468 \\
\hline
\end{tabular}

Based on estimated marginal means. ${ }^{b}$ Correction for multiple comparisons - the smallest significant difference (equivalent to the lack of correction). 
Thus the NHP would also seem to be the optimal questionnaire for patients with endometriosis. Unlike the Hospital Anxiety and Depression Scale (HADS), which is more suitable for stationary health care, the NHP also remains more universal for assessment in ambulatory and home environments [11]. Our study performed using the NHP questionnaire confirmed the above observations. A significantly higher intensity of "pain", "emotional reactions", "sleep disorders" and "physical fitness" variables was noted among the patients suffering from endometriosis. However, no significant differences were found for "social isolation" and "vital energy" variables. Significant disorders were observed in the psychological dimension of endometriosis, which, however, did not have such a negative and intense effect on contact with the environment and general life energy. Unlike endometriosis, which affects primarily the physical status and secondarily the psychological status, many other well-controlled but chronic diseases mostly affect vital energy in NHP research [10]. But even chronic work overload and a bad working environment could cause the sleep disorders measured by the NHP [24].

An important area of functioning, closely related to others, which is subject to deterioration under the influence of symptoms of the disease, is sexual functioning [8]. Dyspareunia in women with endometriosis is 4 times more frequent than in the control group, and it is 5 times more common in women with peritoneal endometriosis [25]. A literature review by Sroślak et al. [8] aimed to present studies on quality of life, including the sexual life of women suffering from endometriosis and the impact of treatment methods on sexual functioning, indicated that both surgical treatment and pharmacotherapy are effective methods of endometriosis treatment, and reducing pain symptoms can contribute to improved sexual functioning [8]. Grandi et al. also observed improvement in the quality of life by SF-36 among patients with endometriosis treated with dienogest with the addition of estradiol [26]. Some specific aspects of social life, such as the influence of endometriosis on work, were researched by Wullschleger et al. with a narrow-oriented questionnaire. Patients' work was strongly affected by endometriosis and improved with surgical treatment [14]. The results of the heavy impact of job restrictions also are in accordance with Nnhoaham et al. [27]. However, according to Łuczak-Wawrzyniak et al. [28], endometriosis does not have to cause deterioration in the quality of life, since it may bring about the deployment of individual resources that allow patients to achieve their goals and important life needs. Women with endometriosis adapt to the disease, which allows them to function in good relationships with people in the immediate environment, implement plans and feel great satisfaction with life [28]. This was directly measured by Kiykac Altinbas et al. [29], where the severity of dysmenorrhea was related with quality of life; it was found that chronic pelvic pain and dyspareunia failed to show a negative effect on QoL. The results are also of importance because of the careful selection of the most advanced stages of endometriosis [29].

Nevertheless, the recruitment strategies of patients with endometriosis also influence the quality of life research. Both physical and mental status vary depending on the primary, secondary or tertiary endometriosis health care centre. Results of the analysis by De Graaff et al. [30] suggest clear differences between patient recruitment according to the health care providing possibilities, which should be considered as a limitation of every study among patients with endometriosis [30]. However, there is no doubt that advanced endometriosis is strongly correlated with low QoL and that radical surgical treatment as a gold standard improves women's lives [31].

In conclusion, since the stage of endometriosis does not correlate with subjective complaints, it seems that an additional routine evaluation of quality of life, including an assessment of the severity and classification of the disease, is warranted. Routine use of the Nottingham Health Profile Questionnaire for patients with endometriosis can improve the assessment of the severity of the disease and evaluate the effectiveness of treatment in the future. Because of the modest sample sizes the conclusions should be drawn cautiously.

\section{Acknowledgments}

Patient enrollment methods, ways of obtaining the research material, and its storage were previously approved by the Director of the Gynecology and Obstetrics Clinical Hospital of the Poznan University of Medical Sciences (specifically approved only for this study on 16 January 2018; Resolution No. 5/2018). The patients provided written informed consent for this study.

\section{Conflict of interest}

The authors declare no conflict of interest.

\section{References}

1. Kotarski J, Polak G. Etiopatogeneza endometriozy. In: Ginekologia. Stomko Z (ed.). PZWL, Warsaw 2008; 303-8.

2. Zabel M, Dzięgiel P. Histologia endometriozy. Ginekol Dyplom 2007; 10: 13-7.

3. Basta A, Brucka A, Górski J, et al. The statement of Polish Society's Experts Group concerning diagnostics and methods of endometriosis treatment. Ginekol Pol 2012; 83: 871-6.

4. Practice Committee of the American Society for Reproductive Medicine. Treatment of pelvic pain associated with endometriosis. Fertil Steril 2008; 90 (Suppl 3): S60-9. 
5. Gao X, Yeh YC, Outley J, et al. Health-related quality of life burden of women with endometriosis: a literature review. Curr Med Res Opin 2006; 22: 1787-97.

6. Cox H, Henderson L, Andersen $\mathrm{N}$, et al. Focus group study of endometriosis: struggle, loss and the medical merry-go round. Int J Nursing Pract 2003; 9: 2-9.

7. Facchin F, Barbara G, Saita E, et al. Impact of endometriosis on quality of life and mental health: pelvic pain makes the difference. J Psychosom Obstet Gynaecol 2015; 36: 135-41.

8. Sroślak K, Ziętalewicz U, Pyrcz P. The impact of endometriosis and modes of its treatment on quality of life and sexual functioning of women - a review of recent research. Przegl Seks 2017; 1: 17-24.

9. Socha B, Kutnohorská J, Zielińska M, et al. The quality of life depending on the patient's condition. J Public Health Nurs Med Rescue 2011; 2: 6-8.

10. Mróz A, Marczewski K. The energy and mobility of the patients treated with maintainance hemodialysis. Ann Univ Marie Skodowskiej Curie 2005; 338: 13-7.

11. Wann-Hansson C, Hallberg IR, Risberg B, Klevsgård R. A comparison of the Nottingham Health Profile and Short Form 36 Health Survey in patients with chronic lower limb ischaemia in a longitudinal perspective. Health Qual Life Outcomes 2004; 2 : 9.

12. Ernstberger T, Köster G, Walde T, Schultz W. The Nottingham health profile-experiences after hip revision arthroplasty. Arch Orthop Trauma Surg 2005; 125: 521-5.

13. Selcuk S, Sahin S, Demirci O, et al. Translation and validation of the Endometriosis Health Profile (EHP-5) in patients with laparoscopically diagnosed endometriosis Eur J Obstet Gynecol Reprod Biol 2015; 185: 41-4.

14. Wullschleger MF, Imboden S, Wanner J, Mueller MD. Minimally invasive surgery when treating endometriosis has a positive effect on health and on quality of work life of affected women. Hum Reprod 2015; 30: 553-7.

15. Hunt SM, McKenna SP, McEwen J, Backett EM, Williams J, Papp E. A quantitative approach to perceived health status: a validation study. Jf Epidemiol Commun Health 1980; 34: 281-6.

16. Garellick G, Malchau H, Herberts P. Specific or general health outcome measures in the evaluation of total hip replacement. Bone Joint J 1998; 80: 600-6.

17. Hunt SM, McKenna SP, McEwen J, Williams J, Papp E. The Nottingham health profile: subjective health status and medical consultations. Soc Sci Med 1981; 15: 221-9.

18. Hunt SM. McEwen J. McKenna SP. Measuring health status: a new tool for clinicians and epidemiologists. J R Coll Gen Pract 1985; 35: 185-8.

19. WHOQOL Group. The World Health Organisation quality of life assessment (WHOQOL): position paper from the world health organisation. Soc Sci Med 1995; 41: 1403-9.

20. Szyguła-Jurkiewicz B, Kowalska M, Mościński M. Jakość życia jako element oceny stanu zdrowia i efektywności leczenia chorych ze schorzeniami układu sercowo-naczyniowego. Folia Cardiol Excerpta 2011; 6: 62-71.

21. Culley L, Law C, Hudson N, et al. The social and psychological impact of endometriosis on women's lives: a critical narrative review. Hum Reprod Update 2013; 19: 625-39.

22. Márki G, Bokor A, Rigó J, et al. Physical pain and emotion regulation as the main predictive factors of health-related quality of life in women living with endometriosis. Hum Reprod 2017; 32: 1432-8.

23. Yildiz N, Topuz O, Gungen GO, Deniz S, Alkan H, Ardic F. Health-related quality of life (Nottingham Health Pro- file) in knee osteoarthritis: correlation with clinical variables and self-reported disability. Rheumatol Int 2010: 1595-600.

24. Liang $\mathrm{Y}$, Wang $\mathrm{H}$, Tao X. Quality of life of young clinical doctors in public hospitals in China's developed cities as measured by the Nottingham Health Profile (NHP). Int J Equity Health 2015; 14: 85.

25. Radomski D, Jarząbek G, Pawlaczyk M, et al. The prevalence of dyspareunia in women with endometriosis. Seksuol Pol 2006; 4: 13-5.

26. Grandi G, Xholli A, Napolitano A, Palma F, Cagnacci A. Pelvic pain and quality of life of women with endometriosis during quadriphasic estradiol valerate/dienogest oral contraceptive: a patient-preference prospective 24 week pilot study. Reprod Sci 2015; 22: 626-32.

27. Nnoaham KE, Hummelshoj L, Webster P, et al. World Endometriosis Research Foundation Global Study of Women's Health consortium. Impact of endometriosis on quality of life and work productivity: a multicenter study across ten countries. Fertil Steril 2011; 96: 366-73.

28. Łuczak-Wawrzyniak J, Szczepańska M, Skrzypczak J. Evaluation of quality of life in women with endometriosis and management method with side effects of the disease. Prz Menopauz 2007; 6: 329-35.

29. Kiykac Altinbas S, Bayoglu Tekin Y, Dilbaz B, Dilbaz S. Evaluation of quality of life in fertile Turkish women with severe endometriosis. J Obstet Gynaecol 2015; 35 : 49-52.

30. De Graaff AA, Dirksen CD, Simoens S, et al. Quality of life outcomes in women with endometriosis are highly influenced by recruitment strategies. Hum Reprod 2015; 30: 1331-41.

31. Fritzer N, Hudelist G. Love is a pain? Quality of sex life after surgical resection of endometriosis: a review. Eur J Obstet Gynecol Reprod Biol 2017; 209: 72-6. 